\title{
Aportes de la antropología feminista para el debate local sobre la prostitución
}

\section{Deborah Daich}

CONICET - Universidad de Buenos Aires. Instituto Interdisciplinario de Estudios de Género (IIEG). Buenos Aires, Argentina.

Correo electrónico: deborahdaich@yahoo.com.ar

Doctora en Antropología, Investigadora CONICET, docente del Departamento de Ciencias Antropológicas,

FFyL, UBA. Integrante de la Colectiva de Antropólogas Feministas, IIEGE, FFyL, UBA

\section{Resumen}

Cuando se discute, en la arena pública local, los modos posibles de regulación del mercado del sexo, en particular de la prostitución, así como de ponderar los efectos de la campaña antitrata en términos de vulneración de derechos de las trabajadoras sexuales y las personas en situación de prostitución, pareciera que los puntos de vista no están, en el mejor de los casos, debidamente informados y en otros, simplemente rozan la deshonestidad intelectual. Así pues, este trabajo pretende recuperar las genealogías feministas que explican las distintas posturas respecto del mercado del sexo y que brindan, también, algunas claves de lectura importantes a la hora de abordar los distintos modelos legales de regulación de la prostitución.

\section{Contributions of feminist anthropology to the local debate on prostitution}

\begin{abstract}
In local public arena discussions on the possible ways of regulating the sex market, in particular prostitution, as well as when weighing the effects of the anti-trafficking campaign in terms of sex workers' rights violation, it seems that different points of view are, in the best of cases, not properly informed, while in others they simply border on intellectual dishonesty. Thus, this work aims to recover the feminist genealogies that explain the different positions regarding the sex market and that also provide some important reading keys when dealing with the different legal models of regulation of prostitution.
\end{abstract}

Recibido:

13 de noviembre de 2017

Aceptado:

24 de mayo de 2018

\section{Palabras clave}

Prostitución; Feminismo; Modelos de Regulación; Genealogía; Mercado del sexo

\section{Key words}

Prostitution; Feminism; Models of Regulation; Genealogy; Sex market 


\section{Contribuições da antropologia feminista no debate local sobre a prostituição}

Palavras-chave

Prostituição; Feminismo; Modelos Legais de Regulação; Genealogia; Mercado do sexo
1. De un tiempo a esta parte, las políticas antitrata han devenido en políticas dirigidas, en verdad, al mercado sexual todo. La narrativa abolicionista hegemónica que define la prostitución como violencia contra las mujeres y como fenómeno inseparable de la trata (o en palabras de sus militantes, como "las dos caras de la misma moneda") ha calado en las políticas de forma tal que la lucha contra la trata de personas es, hoy en día, la lucha contra la explotación sexual y, en definitiva, contra el trabajo sexual. Ver, por ejemplo, Daich y Varela (2014 y 2015). Para un desarrollo de la "migración" de la campaña antitrata de los espacios transnacionales hacia nuestro país, ver Varela (2015).

\section{Resumo}

Ao discutir, na arena pública local, as maneiras possíveis de regulamentar o mercado sexual, em particular a prostituição, bem como sopesar os efeitos da campanha contra o tráfico em termos de violação dos direitos das trabalhadoras do sexo e pessoas em situação de prostituição, parece que os pontos de vista não são, na melhor das hipóteses, devidamente informados e, em outros, simplesmente roçam a desonestidade intelectual. Assim, este trabalho tem como objetivo recuperar as genealogias feministas que explicam as diferentes posições em relação ao mercado sexual e que também fornecem algumas chaves importantes de leitura ao lidar com os diferentes modelos legais da regulação da prostituição.

\section{Introducción}

Cuando en el año 2011 escribí el artículo “¿Abolicionismo o reglamentarismo? Aportes de la antropología feminista para el debate local sobre la prostitución" (Daich, 2012), apenas comenzaba a investigar sobre la temática del mercado del sexo en Buenos Aires. Entonces ensayaba algunas preguntas respecto de los límites de las distintas posiciones y modelos de regulación de la prostitución que se habían sucedido en la Argentina (reglamentarismo, abolicionismo y propuestas de reconocimiento del trabajo sexual) y proponía a la antropología feminista como una herramienta privilegiada, capaz de enriquecer el debate local. Desde entonces, y como reza el dicho popular, mucha agua ha corrido bajo el puente. Sin embargo, el tiempo transcurrido no parece haberse traducido en mayor claridad conceptual a la hora de discutir, en la arena pública local, los modos posibles de regulación del mercado del sexo, en particular de la prostitución, así como de ponderar los efectos de la campaña antitrata en términos de vulneración de derechos de las trabajadoras sexuales y las personas en situación de prostitución. ${ }^{1}$

Por supuesto que cuando hablamos de problematizaciones en la arena del debate político, se trata siempre y finalmente de pugnas de sentidos, de luchas simbólicas - con correlatos y efectos materiales - mediante las que se busca instaurar determinados significados y obtener legitimidad a través de, por ejemplo, la sanción de leyes. No estoy cuestionando que se trate, finalmente, de la pugna por inscribir el punto de vista de un grupo particular sino de que, cuando el debate implica hablar de prostitución, ese punto de vista no está, en el mejor de los casos, debidamente informado y en otros, simplemente roza la deshonestidad intelectual.

La problemática es bien compleja: la prostitución no es un fenómeno uniforme ni unívoco, y su heterogeneidad se complejiza con las diferentes formas que asume no solo en distintos contextos y mercados, sino también en términos históricos y culturales. Pero además, ya sugería Dolores Juliano (2002) que la 
prostitución no puede ser considerada como una actividad aislada pasible de ser analizada dentro del universo cerrado de su concreción.

Así, la prostitución no se trata de una cuestión exótica o marginal. Antes bien, requiere vislumbrar un sistema que nos involucra a todos y todas; que vincula a diferentes actores en una serie de relaciones que constituyen una intrincada y compleja trama de significados, y que no están exentas de poder. Implica atender a los procesos del capitalismo tardío, al mercado del trabajo, a los flujos de las migraciones, a las políticas de y entre naciones, a las demandas de movimientos sociales, entre otros. Implica también abordar el fenómeno con una mirada que tenga en cuenta distintas dimensiones, tales como clase, género, etnia y sexualidad.

Asimismo, la prostitución refiere tan solo a una de las múltiples actividades posibles dentro de un mercado sexual mayor del que aquella no puede desligarse aunque, a los fines analíticos y de investigación, las cercenemos. Cuando hablamos de prostitución nos referimos a un acto muy específico; en verdad, a tan solo una de entre tantas actividades posibles dentro de un mercado sexual mayor que incluye, por ejemplo, la pornografía, el masaje erótico, el sexo telefónico y virtual, el striptease y baile erótico, los servicios BDSM, entre tantas otras. De aquí que las investigaciones que vienen abordando el sexo comercial utilicen la expresión mercado del sexo. Como bien lo explican Adriana Piscitelli (2005) y Laura Agustín (2005), el término prostitución invisibiliza toda esa diversidad y también puede oscurecer la compresión de que, de hecho, hay un mercado y una demanda. Focalizarse en la prostitución suele dejar de lado esta diversidad, así como deja de lado la atención sobre la demanda y los diversos deseos y motivaciones de quienes procuran servicios sexuales. Pero además, según Adriana Piscitelli, hay otro problema con el término prostitución, $\mathrm{y}$ es que sus definiciones comunes no permiten pensar en los diversos tipos de inserción en este mercado, sobre todo de aquellos tipos en los que puede no haber un contrato explícito de intercambio de sexo por dinero. Es decir, tenemos que pensar que las inserciones en el mercado del sexo son variadas y no siempre responden a la compra-venta explícita de un servicio sexual. ${ }^{2}$

Ahora bien, en tanto no se trata de un fenómeno aislado, el mercado del sexo refleja las desigualdades, las jerarquías y el sexismo imperantes en la sociedad en su conjunto; está atravesado por las marcas de género, clase, etnia y edad que habilitan desigualdades y actualizan relaciones de poder. Así pues, la prostitución es un sistema estratificado donde las distintas jerarquías sociales operan de manera diferencial en la reproducción de las desigualdades y donde, sin lugar a dudas, la jerarquía de género juega en la distribución desigual de poder y la reproducción de la violencia. Un sistema donde la unidad de poder, dinero, sexo y género es insumo cotidiano para la estigmatización. Como otras labores, especialmente las destinadas a los sectores populares, el trabajo sexual comporta distintos grados de explotación, coerción, sometimiento y violencia pero, a diferencia de otros quehaceres, es socialmente estigmatizado. ${ }^{3}$

Por supuesto que el trabajo sexual, o la prostitución, es una institución patriarcal, así como también lo es el matrimonio o el trabajo doméstico, para dar tan solo dos ejemplos. Sin embargo, estos últimos no suscitan tantas ansiedades como lo hace el tema de la prostitución, ¿por qué?

Aquí es cuando el asunto más se empantana. En parte, quizás, porque la respuesta a aquella pregunta implica posicionarse política y conceptualmente; implica preguntarse cuál es (si es que acaso hay uno) el locus por excelencia
2. Por ejemplo, en Brasil, hay una figura conocida que es "el viejo que ayuda"; se trata de un personaje que implica que las jóvenes de sectores populares - muchas de las cuales no son consideradas prostitutas- se relacionan con varones mayores, de los que obtienen algún apoyo económico y con los que mantienen una serie de intercambios sexo-afectivos. Claudia Fonseca (2004) explica cómo esta “categoría de compañero masculino" aparece tanto en los relatos de las prostitutas como en el de las jóvenes que no lo son. (continúa en página 19)

3. No estoy hablando aquí de inserciones forzadas en el mercado del sexo sino de quienes participan de él como fruto de una opción razonada y sopesada frente a otras alternativas laborales disponibles. 
4. Las propagandas de Mr. Múscude limpieza, suelen reproducir los estereotipos tradicionales acerca de los roles de género que asignan a las mujeres el espacio de lo doméstico (lo privado, la familia) y reservan para los varones la gestión del espacio público (como la política, por ejemplo). Además, las propagandas de Mr. Músculo se caracterizan por presentar a una mujer que, frente a una tarea doméstica como la limpieza de la cocina o el baño, es auxiliada por una suerte de superhéroe - Mr. Músculo-que resuelve sus problemas al brindarle el producto. Aparece, así, con matices, la imagen estereotipada de la mujer "débil que necesita protección". lo, como las de todos los productos

de la opresión y subordinación de las mujeres, e implica también preguntarse cuál es la relación entre género y sexualidad. Conlleva preguntarse por qué, en términos estructurales, sería más peligroso para el estatus de las mujeres que existan servicios sexuales pagos a que existan propagandas de $\mathrm{Mr}$. Músculo, ${ }^{4}$ o por qué sería más dañino ser trabajadora sexual que ser trabajadora de casas particulares.

Algunas posturas pretenden hegemonizar el debate, y reemplazan el ejercicio del pensamiento crítico por la invisibilización de otros desarrollos teóricos y de las demandas de determinados colectivos, como el de trabajadoras sexuales. Pero además, estas posturas tienden a obturar el debate al presentar representaciones monolíticas que, mediante la apelación a imágenes sensoriales fuertes, retratan al trabajo sexual como pura violencia o como una violación (Daich, 2017). Estos posicionamientos, generalmente informados por un discurso feminista abolicionista, suelen incluso negar (por acción u omisión) que desde el comienzo mismo del feminismo como movimiento emancipatorio, las conceptualizaciones acerca de la sexualidad y de la prostitución eran tópico constante de discusión. Asimismo, son posiciones que, por lo general, suelen echar mano de otra operación discursiva que involucra a los modelos de regulación de la prostitución. Generalmente suele señalarse la existencia de tres modelos: prohibicionismo, reglamentarismo y abolicionismo, con lo cual se invisibiliza al cuarto modelo, el de legalización o modelo laboral, impulsado desde los años setenta del siglo XX por las organizaciones de trabajadoras sexuales a lo largo y a lo ancho del globo. En el mismo movimiento, suelen subsumir estas últimas iniciativas dentro del modelo reglamentarista (que corresponde al paradigma de pensamiento de fines del siglo XIX y comienzos del XX), lo que genera confusión y atribuye, a las iniciativas de reconocimiento de derechos de estos colectivos, características no deseadas ni reivindicadas.

Así pues, este trabajo pretende recuperar las genealogías feministas que explican las distintas posturas respecto del mercado del sexo y que brindan, también, algunas claves de lectura importantes a la hora de abordar los distintos modelos legales de regulación de la prostitución.

\section{De feminismos y feministómetros}

Recientemente, en una entrevista radial, una referente de la Campaña Abolicionista ${ }^{5}$ reflexionaba acerca de las jóvenes mujeres que se incorporan actualmente al movimiento feminista argentino:

5. La Campaña Abolicionista "Ni una mujer más víctima de las redes de prostitución", formada en el 2007, reúne a distintas organizaciones, algunas de ellas de larga trayectoria, como la Asociación de Trabajo y Estudio sobre la Mujer, "25 de noviembre" (ATEM). Puede consultarse su página web: http:// campaniaabolicionista.blogspot. com.ar\%. (continúa en página 20)

6. http://www.radiokermes.com/index.php/component/k2/item/7947las-redes-de-prostitucion-financian-el-discurso-reglamentarista\#. WcoUdZ2liSE.facebook. Entrevista a Marcela D'Angelo, integrante de la Campaña Abolicionista “ $\mathrm{Ni}$ una mujer más víctima de las redes de prostitución", 26-9-2017.
Está bárbaro que se acerquen al feminismo pero lo que veo es que tienen que, de alguna manera, empezar a agarrar la genealogía feminista, a reconocer historia, no todo empieza cuando yo llego y no necesito leer nada porque quiero inventar todo (...). Muchas veces es una cáscara de feminismo y cuando vos vas rascando ves, por ejemplo, que se dice feminismo y se defiende la prostitución, la reglamentación de la prostitución, o te dicen: ay bueno, yo todavía no tengo decidido. Pero el feminismo concede derechos, el feminismo reconoce al opresor, entonces, si no ahondamos en eso... Está muy bien que se acerquen, pero que se acerquen porque si no retrasan el movimiento porque, por ejemplo, dicen que hay feministas que son reglamentaristas, menos mal que no se les ocurrió a las provida decirse feministas, porque hubieran retrasado la discusión del aborto... Hay que leer un poco de historia del feminismo, saber qué es lo que se sostiene dentro del feminismo, porque decirse feminista sale gratis y a nosotras no nos salió gratis. ${ }^{6}$ 
No existe un único feminismo, sino múltiples feminismos que convergen en un movimiento dinámico, no exento de contradicciones o polémicas; se trata de un movimiento plural y diverso. Sin embargo, algunas militantes feministas, como la referente de la Campaña Abolicionista citada, al tiempo que señalan la importancia de recuperar las genealogías feministas, las desconocen o las niegan. Pienso, como señalaba Eli Bartra (a propósito de otra discusión feminista) que aquí también "existe una gran miopía política o, de plano, una enorme mala fe" (2010: 199). Estas militantes ponen en uso el llamado "feministómetro": la ponderación respecto de quién es o no feminista de acuerdo con los propios parámetros. Así, por ejemplo, en la misma entrevista, la referente señalaba: "el feminismo defiende derechos y nadie puede decirse feminista y defender la reglamentación de la prostitución, es como si fuera un oxímoron, dos cosas opuestas". Esta afirmación maniquea niega la historia misma del feminismo al tiempo que colabora en generar perplejidad, porque pone a jugar cuestiones que, como se verá párrafos más adelante, no están en la mesa de discusión; nadie está reclamando un modelo reglamentarista. Quizás la confusión no sea intencional y la errónea referencia a la reglamentación simplemente se refiera al hecho de no aceptar la reivindicación de las trabajadoras sexuales de su actividad como trabajo.

Pero entonces, ¿cuál es esa historia feminista? Por cuestiones de espacio no podría aquí reseñarla completa en su diversidad y complejidad, pero sí pueden consignarse algunos hitos clave y algunas consideraciones respecto de la construcción de la sexualidad y la prostitución en el pensamiento feminista del siglo XIX y de las llamadas batallas del sexo del siglo XX. ${ }^{7}$

\section{La sexualidad a debate: feministas del siglo XIX}

En las aproximaciones al sexo y la sexualidad, las feministas - señalan las historiadoras Dubois y Gordon (1983) - heredamos dos tradiciones en conflicto. Por un lado, la tradición más fuerte y permanente, la hegemónica en el movimiento de mujeres del siglo XIX, se ha dirigido a los peligros del sexo. Otra perspectiva, menos desarrollada entonces, se dirigía a las posibilidades del sexo. Ambas tradiciones, al igual que la sociedad de entonces, eran heterosexistas. Y ambas líneas feministas de pensamiento - la que enfatizaba el peligro y la que enfatizaba el placer - a menudo eran moralistas.

La corriente principal del feminismo del siglo XIX, sugieren estas autoras, tuvo un importante papel en la creación del sentimiento de peligro sexual al señalar los nudos del terror sexual: la prostitución y la violación. Sin embargo, era llamativamente poco el énfasis que estas feministas dedicaban al tema de la violación. La prostitución, en cambio, se erigía en símbolo principal de la coacción sexual masculina.

De acuerdo con Dubois y Gordon, estos grupos feministas fueron enfatizando distintos aspectos del fenómeno de la prostitución. Así, alrededor de los años 1860/1870, sugieren las autoras, se centraron en las presiones económicas que forzaban a las mujeres a entrar al comercio sexual. Luego, dirigieron su atención a la "esclavitud blanca" y a la coerción física que obligaba a mujeres inocentes a involucrarse en el sexo comercial. Estas feministas, en su mayoría sufragistas, exageraban la magnitud del problema y lo hacían porque su definición de prostitución incluía prácticamente a todas las mujeres que se dedicaban al sexo ocasional, sin importar si recibían un pago por ello o no. Exageraban la coacción de la prostitución, por lo que el único rol posible para
7. Como señala Lamas, "si bien las sex wars han ocurrido principalmente en el movimiento feminista estadounidense, su influencia teórica y política ha enmarcado la disputa feminista en todo el mundo. Esto responde a lo que Bolívar Echeverría (2008) calificó como la 'americanización de la modernidad', o sea, que la tendencia principal de desarrollo de la vida económica, social y política es la norteamericana. Por eso no es raro que se haya dado una americanización de debate feminista mundial, evidente en el papel determinante que han tenido las publicaciones y el activismo de las feministas estadounidenses" (2017: 161). 
las mujeres en prostitución era el de víctimas pasivas. Asumían que la prostitución era algo tan degradante que nadie la elegiría libremente. Por lo que la "mujer perdida" era vista siempre como una víctima, no solo de la dominación masculina, sino también del secuestro, la violencia, el hambre, y/o la seducción (Dubois y Gordon, 1983).

Lo interesante es que estas autoras plantean que este feminismo no solo no pudo poner en tela de juicio tamaña explicación simplificada y condescendiente de la prostitución, sino que hizo de ella un aspecto central de su idea de opresión femenina. Este énfasis en la opresión (y en el peligro) terminó por abonar y legitimar una moralidad sexual que dividía las mujeres en buenas y malas, y la necesidad de "rescatarlas" para incluir a las víctimas en el mundo de las buenas (Dubois y Gordon, 1983).

En el siglo XIX, la mayor violencia sexual y física contra las mujeres, al igual que hoy, sucedía en los hogares. La violación en el matrimonio y la violencia doméstica (dentro de ciertos límites) no eran un delito, y el incesto estaba a la orden del día. Pero en ese entonces las feministas aún no habían podido politizar y problematizar el ámbito de lo privado. Así, el temor a la prostitución representaba también un temor a la violencia física directa pero, sugieren Dubois y Gordon (1983), "de manera desplazada". De todas formas, algunos peligros encarnados en el matrimonio debían ser enfrentados, entre ellos el peligro de las enfermedades venéreas; las feministas consideraban implícitamente que la prostitución era su origen, por lo que la monogamia era vista como la única fuente de seguridad. También en el marco del matrimonio, el sexo ofrecía otros peligros, como las relaciones sexuales forzadas o los embarazos no deseados. De aquí que el control de la concepción se tradujera, muchas veces, en la negación de las relaciones sexuales.

Este movimiento, al centrarse en el peligro sexual, tuvo una activa campaña en contra de la prostitución, con tendencias que fueron cada vez más represivas. Entre los años 1860-1870 llevaron adelante la campaña contra la regulación estatal de la prostitución con diversos argumentos, entre ellos, denunciaban que protegía el vicio masculino y por eso reivindicaban un único patrón de sexualidad sobre la base del ideal de castidad femenina. Criticaban la agresiva sexualidad masculina, pero también expresaban cierta ambivalencia en relación con las prostitutas que no querían ser salvadas ni reformadas:

"He visto muchas ciudades", declaraba [Josephine] Butler, "y nunca encontré una desdichada mujer que no tuviera todavía cierto recato" pero cuando llegó a las ciudades donde estaba vigente la regulación se encontró con prostitutas impenitentes que "francamente no me gustaron. Parecían frías y duras, y me contaron en un tono completamente desprovisto de emoción que estaban registradas, que no hacían ningún mal ni causaban ningún daño, porque iban regularmente a su revisión" (Walkowitz, 1993: 401).

Judith Walkowitz (1993) muestra cómo estas reformadoras femeninas que empatizaban con las prostitutas en tanto mujeres "caídas" por la presión económica o la seducción masculina, también odiaban su "pecado" y mantenían una posición ambivalente entre mujeres buenas y malas.

Con el tiempo, las tendencias represivas de esta campaña aumentaron, dejando a un lado los aspectos liberadores y que buscaban cierta protección contra la violencia, y pasaron a presionar ya no por la abolición de la reglamentación sino por la abolición de la prostitución en sí. 
Pero así como había experiencias de resistencia a la cultura sexual represiva del siglo XIX, ${ }^{8}$ también había otros discursos políticos dentro del movimiento de mujeres. Señalan Dubois y Gordon (1983) que, aunque se trataba de una visión minoritaria, una corriente pequeña pero continua de feministas insistía en que el aumento de la actividad sexual femenina no era incompatible con la dignidad de la mujer. Esta corriente comenzó con los movimientos utópicos y a favor del amor libre de los años 1820-1840. Estas mujeres cuestionaron que el deseo fuese exclusivamente masculino y la obligatoriedad de la familia y el matrimonio como los legítimos canales para la sexualidad. A partir de la década de 1880, algunas de estas feministas comenzaron a plantear una sexualidad no organizada alrededor del orgasmo masculino. Esta nueva generación de feministas, sostienen las historiadoras, ya no tenía miedo de que las tildaran de prostitutas ni veían a las prostitutas como simples víctimas inocentes. Pero, fieles a la época, y aunque contradijera sus propias experiencias, seguían aceptando una definición masculina y heterosexual del sexo (Dubois y Gordon, 1983).

\section{La sexualidad a debate: las batallas del sexo del siglo XX}

Estas distintas posiciones respecto del sexo y la sexualidad fueron reactualizadas en lo que se conoció como las sex wars, una serie de debates y posiciones encontradas entre los feminismos norteamericanos a partir de los años setenta, especialmente entre el movimiento antipornografía y la corriente "prosex", que culminaría en un enfrentamiento público en la Conferencia de Barnard de 1982.

Las diferentes posiciones feministas respecto de la prostitución eran bien variadas, pero el debate entonces se polarizó en dos posturas contrarias. Como bien sugiere Adriana Piscitelli (2005), de un lado se presentaba al sexo como la raíz de la opresión, y a la prostitución como el caso paradigmático, por lo que las prostitutas debían verse como víctimas de esa violencia, como objetos sexuales y pasivos. Del otro lado, se presentaba al sexo como fuente de poder y a la prostituta como símbolo de la autonomía sexual de las mujeres y amenaza potencial al control patriarcal de la sexualidad. Ahora bien, estas imágenes deben tomarse, en verdad, como tipos ideales que habitan la retórica feminista, ya que la realidad de las inserciones en el mercado del sexo son infinitamente más variadas que estas posiciones maniqueas (Piscitelli, 2005). Otras posturas piensan en el sexo como terreno de disputa antes que como campo fijo de posiciones de género y poder, por lo que el orden sexista imperante no es enteramente determinante. Por lo mismo, la posición de la prostituta no puede ser reducida a la de un objeto pasivo subordinado a las prácticas sexuales masculinas, sino que debe leerse como un espacio de agencia donde se negocia y se hace uso activo del orden sexual existente (Piscitelli, 2005).

Durante la segunda ola feminista, el feminismo radical acuñó el lema "Lo personal es político", con el que señalaron que aquellas áreas de la vida que se consideraban privadas o íntimas también estaban atravesadas por relaciones de poder. Por eso fue también en este momento cuando se llevó adelante la crítica a la forma en que la dominación masculina moldea la sexualidad femenina por medio de prácticas (como la violación) y de creencias (como la del orgasmo vaginal) y, al mismo tiempo, se replican los esfuerzos de las mujeres por definir y explorar sus propias sexualidades: autoexploración, masturbación, sexualidad lesbiana, etc. Se lleva adelante la crítica a la revolución sexual -que, se evidenciaba, había tenido lugar en los términos masculinos - la crítica a la violencia masculina y a la heterosexualidad obligatoria y sus instituciones.
8. Mujeres que no se avergonzaban de su vida sexual ni de sus orgasmos (fueran prostitutas o no) y mujeres que se travestían y se casaban con otras mujeres, entre otros casos. 
9. No todas las representantes del feminismo cultural estaban a favor del determinismo biológico. Como todo movimiento, no era monolítico.
A mediados de los años setenta, algunas feministas radicales comenzaron a plantear lo que luego se conocería como feminismo cultural. Si el feminismo radical planteaba que las diferencias entre varones y mujeres eran sociales y no biológicas; el feminismo cultural alentó una visión fija de las diferencias entre varones y mujeres, y sostuvo explicaciones cuasibiológicas de las diferencias de género. ${ }^{9}$ El feminismo cultural sostuvo que había un estilo de vida femenino que era bueno y positivo por naturaleza, y que se oponía a una forma masculina agresiva y violenta (Bronstein, 2001). Las conceptualizaciones de género, dentro de esta perspectiva, se volvieron esencialistas. Así, mientras que el feminismo radical había planteado la violencia masculina como una herramienta política, el feminismo cultural la acercaba a una supuesta biología masculina. A pesar de las críticas feministas a estas visiones, algunas de ellas se tornaron populares y, como sugiere Carolyn Bronstein (2011), fueron funcionales a las explicaciones del movimiento antipornografía, que trataba cada representación del deseo sexual masculino como violencia contra las mujeres. De hecho, muchas referentes de dicho movimiento eran feministas radicales devenidas culturales. El feminismo cultural, según Alice Echols (1989), equipara la liberación de la mujer al desarrollo de una contracultura femenina capaz de reemplazar a la cultura dominante. El feminismo cultural conlleva cierto elogio e idealización de la feminidad, cuando no una esencialización. Así, por ejemplo, Robin Morgan afirmaba la existencia de una sexualidad femenina opuesta a la masculina, caracterizada por la afectividad:

\footnotetext{
Cada mujer de las que estamos aquí siente en las tripas la diferencia que hay entre su sexualidad y la de cualquier hombre educado en la sociedad patriarcal (...) y siente que el énfasis sobre la sexualidad genital, la cosificación, la promiscuidad, la falta de compromiso emocional y la dura invulnerabilidad eran el estilo masculino y que nosotras, como mujeres, valoramos más el amor, la sensualidad, el humor, la ternura, la entrega (en Echols, 1989: 97).
}

Al decir de Alice Echols, las feministas culturales (que lograron cierta hegemonía dentro del movimiento antipornografía) construyeron una sexualidad femenina pasiva, difusa, orientada hacia lo interpersonal y benigna versus una sexualidad masculina compulsiva, irresponsable, orientada hacia lo genital y letal en potencia. Según Andrea Dworkin, la sexualidad masculina es "la materia prima del asesinato, no del amor", por lo que la sexualidad y la violencia están íntimamente ligadas y encuentran su expresión cultural en la pornografía (Echols, 1989).

De acuerdo con esta autora, las feministas radicales adoptaron una aproximación dualista a la sexualidad que reconocía tanto el placer como el peligro; combinaban la proclama por la autoexploración sexual y los manuales feministas de sexualidad con las acciones del movimiento antiviolación sin que uno socavara la efectividad del otro. En cambio, en el análisis del feminismo cultural, "el peligro sexual define de tal manera la vida de las mujeres que excluye toda consideración del placer. Al contrario que las feministas radicales, que, en general, situaban el origen de la opresión de las mujeres en la familia nuclear, las feministas culturales están de acuerdo con Andrea Dworkin en que el núcleo de la opresión sexual es la utilización de las mujeres como pornografía, la pornografía como lo que son las mujeres" (Echols, 1989:95).

En sus inicios, el movimiento antipornografía estaba dirigido contra las imágenes de violencia sexual presentes en los medios hegemónicos, en especial en lo que hacía a la publicidad. Luego, se centraría en la pornografía, incluso en la que no era explícitamente violenta, y quizás su faceta más conocida tenga que 
ver con los intentos de Catharine MacKinnon y Andrea Dworkin, a mediados de los años ochenta, de introducir leyes antipornografía.

Los grupos más resonantes dentro de este movimiento fueron Women Against Violence Against Women (WAVAW), Women Against Violence in Pornography and Media (WAVPM) y Women Against Pornography (WAP), los cuales surgieron entre los años 1976 y 1979 en Los Ángeles, San Francisco y Nueva York, respectivamente. Sus principales acciones tuvieron que ver con ejercer presión sobre las corporaciones para que retiraran las campañas publicitarias que celebraban la violencia sexual y también aquellas que reforzaban los estereotipos de género. Como organizaciones autónomas, compartían ideales en contra de la violación, la violencia, el acoso sexual y otras formas de violencia sexual. Asimismo, sus posiciones respecto de la pornografía eran disímiles. Entre las integrantes de WAVPM se encontraban Diana Russell, Kathleen Barry y Susan Griffin, por ejemplo. Esta agrupación fue la primera en organizar una serie de protestas en San Francisco, en las que señalaban que las películas y libros porno eran centrales a la opresión de las mujeres, por cuanto creaban un clima hostil que enseñaba a los varones a ver a las mujeres como meros objetos sexuales. También realizaban protestas en los clubs de strippers y en bares y salones donde se realizaban performances sadomasoquistas. En palabras de Andrea Dworkin, la pornografía enseñaba a los varones a odiar, usar y lastimar a las mujeres (Bronstein, 2001). En 1979, se formaba WAP a partir de la reunión de reconocidas feministas radicales como Susan Brownmiller, Robin Morgan y Gloria Steinem. Con WAP - que más adelante, junto con otros grupos, se reconvertiría en la Coalition Against Trafficking in Women (CATW) comenzó una verdadera cruzada en contra de la pornografía y casi toda imagen sexual. Sus integrantes sostenían que la pornografía reforzaba la idea de que el acceso sexual a los cuerpos de las mujeres era el derecho de todo hombre. Y sostenían también un vínculo entre consumo de pornografía y aumento de violencia hacia las mujeres que nunca pudo ser empíricamente demostrado (Bronstein, 2001).

Estas organizaciones emprendieron campañas varias en contra de la pornografía, entendiéndola como violencia contra las mujeres ("la pornografía es la teoría, la violación es la práctica", al decir de Robin Morgan) y, a través de Catharine Mackinnon y Andrea Dworkin impulsaron ordenanzas que prohibían la pornografía. Si bien estas últimas no tuvieron éxito (porque violaban la primera enmienda norteamericana, la libertad de expresión), dieron cuenta de una alianza muy particular: habían sido sostenidas por asociaciones vecinales, republicanos conservadores, fundamentalistas de derecha y miembros de la coalición norteamericana Mayoría Moral. Como muestran Lisa Duggan y Nan Hunter (2006), el movimiento antipornografía preparó el terreno para iniciativas conservadoras de todo tipo. Entre ellas, iniciativas para eliminar subsidios al arte erótico, por ejemplo, cuando en el año 1989 el Corcoran (el Museo de Arte de Washington) suspendió la muestra de Robert Mapplethorpe. O vale citar, como otro ejemplo, cuando en el año 1990 el director del Museo de Arte Contemporáneo de Cincinnati tuvo que enfrentar cargos "por uso de material obsceno" debido a una exhibición de fotos del mismo artista. Sobre este punto hay hasta una película, Dirty Pictures, interpretada por James Wood.

Como bien sugieren Carole Vance y Ann Barr Snitow (1984), el movimiento antipornografía se caracterizó por una confusión de categorías y una dificultad para establecer distinciones entre pornografía violenta y pornografía, entre pornografía y sexo, y entre sexo y violencia. Justamente la segunda ola feminista se había resistido a tales confusiones conceptuales; por ejemplo, 
10. De aquí la alianza posible con las derechas, puesto que el backlash profamilia se apoyó justamente en el discurso del peligro para atacar las conquistas feministas e intentar restaurar un imaginario de "relaciones sexuales tradicionales", en las que sexualidad se liga a reproducción. el movimiento antiviolación había asumido que las causas de la violencia contra las mujeres eran complejas y no podían reducirse a una sola; y fue particularmente atento a separar conceptualmente el sexo de la violencia en sus elaboraciones respecto de la violación.

¿Es el sexo la raíz principal de la opresión de las mujeres o es la opresión sexual una de tantas expresiones de la inequidad de género?, se preguntan Carole Vance y Ann Snitow. Sin duda, el movimiento antipornografía consideraba al sexo central en la opresión de las mujeres, por lo que privilegiaban la sexualidad como causa de todo el sistema de género.

En 1982, Barnard (reconocido centro de Estudios de las Mujeres que funciona en el ámbito de la Universidad de Columbia) fue el escenario de la IX Conference The Scholar and the Feminist, que estuvo dedicada al tema de la sexualidad. Con este encuentro, se afirmó lo que se llamó las Feminist Sex Wars o Sex Wars a secas, que no es más que la expresión pública de una serie de tensiones y debates respecto de la sexualidad al interior del movimiento feminista. El contexto era el de la hegemonía del movimiento antipornografía, el que paradójicamente contaba con apoyos como el de Mayoría Moral y también del backlash antifeminista y profamilia (Wilson, 1983). Este movimiento se opuso al encuentro y lo boicoteó, quizás porque no había representantes de sus miembros entre las feministas que lo organizaron (aunque sí participaron de los grupos de trabajo). Los grupos que se manifestaron en contra de la reunión de Barnard - entre ellos, WAP - clamaban por una "sexualidad feminista" y "en contra del sadomasoquismo", y acusaron a las organizadoras de apoyar "formas patriarcales" y "antifeministas" de sexualidad tales como el sadomasoquismo o la pedofilia (Wilson, 1983). Con esas afirmaciones, intentaban clausurar las discusiones respecto de la sexualidad y también atacar a quienes no formaban parte del movimiento antipornografía. Para el caso de las acusaciones de sadomasoquismo, por ejemplo, se dirigían en parte a la antropóloga Gayle Rubin, que formaba parte de Samois, un grupo feminista lésbico BDSM.

Algunas autoras han planteado que el debate se construyó en torno a la tensión placer-peligro implicada en la sexualidad de las mujeres. Mientras que un sector del feminismo insistió en el peligro y denunció la sexualidad masculina como la fuente primaria de opresión (y la necesidad de defenderse de ese deseo sexual masculino intrínseco, incontrolable y fácilmente excitable), otras feministas insistieron en el placer y en la importancia de la libre sexualidad para la liberación de las mujeres. Pero como bien sugiere Carole Vance (1989), la sexualidad es simultáneamente campo de limitaciones, represión y peligro, a la vez que de exploración, placer y actuación humana. Este doble enfoque, afirma, es importante porque hablar sólo de placer es ignorar la estructura patriarcal en que vivimos; y porque hablar sólo de peligro, violencia y opresión es ignorar la experiencia de las mujeres como agentes de sexualidad con opciones sexuales.

Si se toma la tensión propuesta por Carole Vance, podría decirse que el movimiento antipornografía enfatizó el peligro, ${ }^{10}$ mientras que las representantes de lo que se llamó movimiento "prosex" recuperaron también la vertiente del placer. Entre las primeras, ya he mencionado a Catharine MacKinnon, Andrea Dworkin, Robin Morgan, Susan Brownmiller y Kathleen Barry. Entre las segundas, se encuentran Gayle Rubin, Carole Vance, Ellen Wilis, Alice Echols, Pat Califia, por mencionar algunas. Unas y otras tienen conceptualizaciones diferentes respecto del género y la sexualidad. Las primeras tienden a confundir sexualidad y género. MacKinnon (1989), por ejemplo, sostiene que la 
sexualidad se deriva del género, en tanto es una dimensión de acuerdo con la cual el género ocurre y se constituye socialmente. Para esta autora, la sexualidad es un constructo social de poder masculino, por eso puede pensar a la violencia sexual como sexo y no como violencia. Para las segundas, en cambio, sexualidad y género no están disociados pero no son idénticos; sus relaciones son situacionales, no universalizables. Es una perspectiva constructivista de la sexualidad que discute con los esencialismos sexuales. Para Rubin (1989), por ejemplo, si bien la sexualidad es un nexo de las relaciones entre los géneros y por ello parte de la opresión de las mujeres está contenida en y mediada por la sexualidad, una teoría sobre la sexualidad no debiera constituirse en una teoría sobre la opresión de género.

\section{De modelos}

En junio de 2017, la Asociación de Magistrados y Funcionarios del Poder Judicial de la Ciudad de Buenos Aires organizó las jornadas "Abolir la prostitución vs. Reconocer el trabajo sexual. Feminismos y marcos legales en disputa". Una de las panelistas, una funcionaria de la Ciudad Autónoma de Buenos Aires $^{11}$ (feminista abolicionista reconocida), expuso sobre el sistema reglamentarista del siglo XIX y comienzos del XX, mencionó el prohibicionismo, el abolicionismo y la trata de personas. Su exposición fue muy similar a otras que había tenido la oportunidad de escuchar, pero esta vez pude preguntarle:

Deborah: Quería saber por qué arrancás hablando de los tres modelos, invisibilizando el cuarto modelo, que es el modelo laboral propuesto por Ixs trabajadorxs sexuales (...) también me parece que esta explicación del reglamentarismo, que es cierto lo que vos señalás, cómo el abolicionismo surge contra el reglamentarismo, contra ese modelo que confinaba a las mujeres a cuasicárceles... pero en tu exposición queda pegado como si fuera hoy y justamente (...) ese reglamentarismo no lo quiere nadie, ni las mujeres en situación en prostitución, ni las trabajadoras sexuales, ni las feministas.

Panelista: Como posiciones, creo que estas son las posiciones. Nunca voy a discutir el modo cómo una persona se define...

Deborah: Perdón, de las posiciones, ¿estás hablando de los tres modelos que mencionaste?

P: Estoy hablando de los tres modelos que mencioné.

D: Falta un cuarto.

P: Bueno, cuando vos decís reconocimiento de trabajo sexual es que ese trabajo va a tener que estar reglamentado de alguna manera.

Cuando abordamos lo que hace a la regulación jurídica en materia de prostitución, podemos distinguir cuatro modelos: reglamentarismo, prohibicionismo, abolicionismo y legalización o modelo laboral (o también descriminalización). Estos modelos tienen su historia y conllevan distintas presunciones morales y posiciones ideológicas; y también impactan de distinto modo en las condiciones de vida de quienes participan del mercado del sexo. Negar que existe el cuarto modelo - o subsumirlo al reglamentarismo - es negar la historia del movimiento de trabajadoras sexuales, es invisibilizar ese colectivo o, peor aún, es tergiversar sus demandas.

Todos estos modelos, a excepción del laboral, comparten una condena moral a la prostitución y están diseñados o bien para controlarla, o bien para eliminarla (Wijers, 2004). En el caso del abolicionismo y del prohibicionismo, la
11. Se trata de la feminista abolicionista Diana Maffia, legisladora de la Ciudad de Buenos Aires (2007-2011) por la Coalición Cívica/ ARI y actualmente directora del Observatorio de Género en la Justicia del Consejo de la Magistratura de CABA. Desde el Observatorio se desarrollan distintas actividades, entre ellas, la formación en temáticas de género dirigida a operadores y operadoras del sistema judicial. 
prostitución es considerada un mal social que debe erradicarse, un fenómeno "incompatible con la dignidad humana". Desde el reglamentarismo, ha sido considerada como un "mal necesario" o "inevitable", por lo que ese modelo ha resultado en formas de control estatal de la salud y en defensa de la moralidad y el orden público.

El reglamentarismo refiere a un modelo concreto de regulación de la prostitución cuyas raíces tienen que ver con ciertas disposiciones napoleónicas e incluye controles sanitarios, espaciales y administrativos. Así, la reglamentación de la prostitución se ha llevado a cabo tanto mediante registros administrativos obligatorios y controles médicos y espaciales, como por medio de la prohibición de ejercer la prostitución de forma clandestina, con la previsión, para estos casos, de sanciones penales. Dentro de este modelo, las prostitutas han sido consideradas "peligrosas" para la salud (en tanto supuestos vectores del "peligro venéreo") y para la moral de la sociedad (en tanto mal ejemplo y amenaza a la honestidad y decencia femenina). Así, fue posible distinguir entre "mujeres públicas" - registradas, sometidas al control sanitario y obligadas, vía las ordenanzas, a cumplir con ciertas pautas de vida- y población femenina en general, "mujeres decentes", para quienes se reservan y naturalizan las tareas de procreación, crianza de los hijos y cuidado del hogar (Guy, 1994; Grammático, 2000). Este modelo fue ampliamente aplicado en el siglo XIX, y para la Argentina, corresponde al período 1875-1936.

El modelo prohibicionista es contemporáneo al abolicionismo; surgió a fines del siglo XIX como una forma de abordaje normativo de la prostitución y, si bien comparte con el abolicionismo el objetivo de acabar con la prostitución, a diferencia de este, plantea que son las prostitutas las principales responsables de la existencia del fenómeno, y por tanto, se las debe perseguir. Así, este modelo prohíbe y sanciona tanto la oferta como la demanda de servicios sexuales; persigue a las prostitutas, a sus clientes y a las terceras partes involucradas. Desde este modelo, las prostitutas son consideradas como infractoras, delincuentes o desviadas.

El abolicionismo surgió en una coyuntura histórica particular y como respuesta a un reglamentarismo que confinaba a las mujeres en casas de tolerancia, que las culpabilizaba, estigmatizaba y etiquetaba; que las obligaba a someterse a controles de salud y a estar bajo la constante vigilancia municipal y policial. Feministas y radicales de Francia se manifestaron en contra de estas medidas que coartaban la libertad de las prostitutas, pero quienes se opusieron más fervientemente a este sistema fueron las feministas y reformistas protestantes, en particular los provenientes de medios ingleses y suizos. Liderada por Josephine Butler, se formó una Federación Abolicionista que lanzó "una cruzada internacional en contra de la reglamentación de la prostitución, considerada como doblemente peligrosa en tanto que implicaba, de una parte, la esclavitud de las mujeres y, de otra, el libertinaje masculino" (Maqueda Abreu, 2009: 6). Así, las primeras abolicionistas reaccionaron contra un sistema opresivo e ineficaz, y en pos de la dignidad de las mujeres (Villacampa Estiarte, 2012). Avanzado el siglo, las feministas presionaron ya no por la abolición de la reglamentación sino por la abolición de la prostitución en sí. Desde este modelo, la prostituta es vista como una víctima, por lo que no debe ser perseguida ni penalizada. Lo que el ideario abolicionista propone es la criminalización del entorno de la prostitución, las "terceras partes". Así, se penaliza a quienes exploten la prostitución ajena de manera directa (proxenetas) e indirecta (dueños de locales que se alquilan, de hoteles, quienes hacen la publicidad, quienes hacen de 
recepcionistas, etc.). En la práctica, esto significa que, aunque no se penalice a la prostituta, se penaliza su entorno y su labor.

Hoy en día se habla incluso de neoabolicionismo. Si el Convenio para la represión de la trata de personas y de la explotación de la prostitución ajena (ONU, 1949) había unificado prostitución y trata, como dos fenómenos "incompatibles con la dignidad y el valor de la persona" abandonando el lenguaje de la moralidad; más adelante, se presentaría el asunto como un caso de violencia contra las mujeres. De esta última construcción participaron feministas abolicionistas, quienes se identificaban con los planteos del movimiento antipornografía (y asociaban sexualidad a violencia y dominación masculina a opresión sexual) y finalmente terminaron por constituir el grupo más influyente en el diseño de políticas abolicionistas:

Para las principales ideólogas de este movimiento, como [Catharine] Mackinnon, o [Kathleen] Barry, presidenta de la Coalition Against Trafficking of Women (CATW), la prostitución constituye una forma más de violencia de género, de dominación del género femenino por el género masculino. Las mujeres sujetas a la prostitución escenifican una dinámica de subordinación. Así, Mackinnon indica cómo las mujeres son prostituidas justamente para ser degradadas y sometidas a tratos brutales sin límite. La prostitución concede a los hombres libertad para acceder a las mujeres, incluidas las prostituidas, mientras que para las mujeres la prostitución representa la pérdida de toda libertad. La prostitución, según Barry, constituye una forma de esclavitud. Esta autora se encargó de trasladar la visión de Mackinnon al plano internacional, básicamente documentando abusos psíquicos y psicológicos sufridos por las mujeres que ejercían la prostitución en América del Sur y África, con el consiguiente incremento de la conciencia internacional acerca de los peligros inherentes a la prostitución. La mujer no puede así consentir libremente en el ejercicio de dicha actividad; la libertad de decisión que se sostiene desde algunas facciones del feminismo constituye un mero espejismo, pues toda prostitución es por propia definición forzada. Este sector del feminismo, que encabeza el neoabolicionismo, sostiene la necesidad de acabar con la prostitución, como una de las manifestaciones de la dominación del género masculino sobre el femenino. Para ello defienden que además de criminalizar las conductas de aquellos que sacan provecho económico de la prostitución, debe proceder a incriminarse las de aquellos que permiten perpetuar esta forma de dominación, los clientes. Las organizaciones no gubernamentales integrantes de esta facción del feminismo han sido las que más activamente han luchado contra la legalización de la prostitución, sosteniendo la identificación de la prostitución con la trata (Villacampa Estiarte, 2012: 90-91).

Para estos feminismos, la prostitución se reveló como el epítome de la dominación masculina: "en palabras de Mackinnon, la prostitución institucionaliza la sexualidad de la supremacía masculina que funde la erotización del dominio y el sometimiento con la interpretación social de lo masculino y lo femenino. Revela que el placer masculino está inextricablemente ligado a la victimización, el daño y la explotación" (Maqueda Abreu, 2009: 19). Este discurso feminista sobre la prostitución se hace eco de un lenguaje más efectivo, ya no es el de la inmoralidad o el pecado, sino el de la violencia contra las mujeres. Al plantear a la prostitución como el símbolo de esa violencia, poco importa si hay consentimiento o coerción, este discurso concibe la prostitución como forzada por definición.

Impulsado por las organizaciones de trabajadoras sexuales desde los años setenta - y con mayor énfasis desde los años ochenta - el modelo laboral plantea el reconocimiento de la oferta de servicios sexuales como una actividad 
12. La Asociación de Mujeres Meretrices de la Argentina (AMMAR), nucleadas desde 1995 en la Central de Trabajadores Argentinos (CTA), viene discutiendo algunas de estas estrategias. En el año 2016 se conformó una agrupación que apoya la reivindicación de los derechos de las y los trabajadores sexuales. Allí confluyen personas de distintas trayectorias profesionales y militantes, entre ellas, varias feministas. Se trata del FUERTSA, Frente de Unidad Emancipatorio por el Reconocimiento de los Derechos de Trabajadorxs Sexuales en Argentina. económica legítima y su legalización se entiende, también, como forma de acabar con la clandestinidad, la violencia y la marginalidad en la que viven las personas que participan del mercado del sexo. Este modelo pondera la ampliación de los derechos civiles y humanos de estas personas, en pos de la defensa de las libertades individuales y del derecho al trabajo. En sus distintas variantes, el modelo puede proponer la legalización de la prostitución por cuenta propia y/o ajena, el derecho a la compra de servicios sexuales y la licitud del comercio sexual. Ningún país lo ha implementado en estado puro; algunos países como Alemania, Australia (Victoria), Nueva Zelanda y Holanda han legalizado el sexo comercial pero con distintas limitaciones, y no siempre en respuesta a los intereses de las organizaciones de trabajadoras sexuales (Wijers, 2004; Maqueda Abreu, 2009).

Al decir de Marjan Wijers, las organizaciones de trabajadoras sexuales han ido creciendo en los últimos años: "han ido aumentando su organización y la batalla contra la exclusión de los mismos derechos que la sociedad confiere al resto de los trabajadores: el reconocimiento del trabajo del sexo como una actividad legítima y la despenalización de los negocios relacionados con la prostitución, de manera que quede regulada bajo preceptos civiles y laborales en vez de penales. Así, el debate dejaría de centrarse en cuestiones morales, siendo las condiciones y los derechos laborales su foco prioritario" (2004: 217).

Desde este modelo, se busca el reconocimiento de derechos laborales, entendiendo que la reivindicación de la ciudadanía laboral es una garantía contra la pobreza, la marginación, los abusos de poder y la explotación (Maqueda Abreu, 2009). Aquí las prostitutas no son víctimas, ni desviadas, ni peligrosas; son sujetos de derechos y trabajadoras. En esta línea, en el ámbito local, las trabajadoras sexuales organizadas vienen propugnando, aún sin éxito, estrategias de descriminalización y reconocimiento de derechos. ${ }^{12}$

\section{A modo de conclusión: de feminismos y formas de gobierno de la prostitución}

Reconstruir algunas de las formas en que los feminismos han problematizado la sexualidad y la prostitución, la construcción de genealogías, responde a "la necesidad de hallar raíces históricas y situadas para nuestras intervenciones teóricas y políticas. Implica preguntar por nuestras antepasadas en procura de un cierto horizonte de comprensión, de un relato que posibilite el anudamiento del sentido, el trazado de continuidades y la ubicación de las rupturas" (Ciriza, 2015: 85). Reconocer la diversidad de conceptualizaciones dentro del movimiento feminista debería llevarnos a un debate sincero y enriquecedor, antes que a encerronas maniqueas. Asimismo, un análisis detenido de estas conceptualizaciones y de las formas en que se tradujeron, luego, en determinadas políticas públicas, debiera darnos las herramientas para posicionarnos de manera más honesta en el debate político.

Es sabido que, en la práctica, ningún modelo pareciera darse de forma "pura". En nuestro país, convive una legislación abolicionista con disposiciones prohibicionistas (como por ejemplo, los artículos de los códigos de faltas que penalizan la oferta de sexo en la vía pública). Por ello, con Cecilia Varela propusimos que era preciso abordar:

la cuestión desde una mirada que privilegia las formas de gobierno de la prostitución. Desde esta perspectiva, podemos incluir en el análisis no sólo las leyes penales 
y su despliegue efectivo sino también las regulaciones de menor jerarquía y las formas de ejercicio del poder de policía junto con las prácticas de intervención y los saberes de los operadores psi y sociales abocados al "rescate" y "reinserción" de las mujeres que ofrecen sexo comercial. Esta perspectiva elude la dicotomía legal / ilegal, y permite capturar la articulación de herramientas legales y extralegales (o cuya legalidad podría ser discutida) en la administración de los ilegalismos de ese espacio social. A su vez, permite atender a los procesos de construcción de los territorios y los sujetos en estos marcos regulatorios. Desde esta perspectiva, todos los modelos suponen e impulsan estrategias de regulación del sexo comercial. Así las políticas de orientación abolicionista y neoabolicionista —generalmente entendidas como la ausencia de regulación- generan a través de las prácticas de los operadores del sistema penal y de la miríada de operadores de "rescate" una nueva forma de regulación. También, desde esta misma perspectiva, las políticas abolicionistas que no plantean formalmente penalizar a las mujeres que ofrecen sexo comercial, pueden hacerlo perfectamente porque en su despliegue práctico generan consecuencias y una infrapenalidad a través de las prácticas de sus operadores (Daich y Varela, 2014: 68).

En dicha investigación, señalábamos cómo en el caso de la CABA, las prácticas inherentes a nuestras formas de gobierno de la prostitución hacían que las trabajadoras sexuales pudieran ser simultáneamente "rescatadas", "investigadas", como responsables de un delito y "sancionadas" por falta de habilitación comercial. Curiosamente, podían estar al mismo tiempo "en peligro" y "ser peligrosas".

Delincuente, infractora y víctima, nunca trabajadora. Pareciera que estas políticas, legitimadas por algunos feminismos (más o menos informados), prefieren pensar siempre en las prostitutas como objetos de intervención, antes que como sujetos de derecho.

\section{Notas}

2 Por ejemplo, en Brasil, hay una figura conocida que es "el viejo que ayuda"; se trata de un personaje que implica que las jóvenes de sectores populares - muchas de las cuales no son consideradas prostitutas- se relacionan con varones mayores, de los que obtienen algún apoyo económico y con los que mantienen una serie de intercambios sexo-afectivos. Claudia Fonseca (2004) explica cómo esta "categoría de compañero masculino" aparece tanto en los relatos de las prostitutas como en el de las jóvenes que no lo son. En el primer caso, suele ser un cliente que se vuelve fijo y que, además del pago regular, brinda una amplia variedad de regalos, se hace cargo de deudas y otras ayudas. En el segundo caso, se trata de un varón al que las mujeres de barrios populares "enamoran" para obtener ayudas; aquí aparece también la idea del enriquecimiento por medio del casamiento o del "casamiento por conveniencia". También pueden pensarse como inserciones que escapan al contrato explícito, a una serie de interacciones (incluso relaciones intencionalmente marcadas por la ambigüedad) que se dan en el marco del "turismo sexual" en diversas partes del mundo y que involucran a turistas varones y mujeres de los países ricos que viajan por países pobres. Esta variedad de relaciones no 
suelen incorporar un contrato explícito de intercambio de sexo por dinero, y han sido muy bien trabajadas por Adriana Piscitelli. (En página 7.)

5 La Campaña Abolicionista "Ni una mujer más víctima de las redes de prostitución", formada en el 2007, reúne a distintas organizaciones, algunas de ellas de larga trayectoria, como la Asociación de Trabajo y Estudio sobre la Mujer, "25 de noviembre" (ATEM). Puede consultarse su página web: http://campaniaabolicionista.blogspot.com.ar/. La Campaña ha organizado anualmente jornadas abolicionistas de discusión y una serie de acciones públicas en los días conmemorativos o de lucha. Ha realizado también acciones de lobby de cara a la reforma de la ley de trata en el año 2012; producto de dicha reforma, la ley actual no distingue entre prostitución forzada y prostitución voluntaria (Daich y Varela, 2014 y 2015). Sobre el abolicionismo feminista porteño ver Daich (2017), y para un breve mapeo de organizaciones abolicionistas y antitrata ver Varela (2012). (En página 8.) 


\section{Q Referencias Bibliográficas}

Agustín, Laura. 2005. Trabajar en la industria del sexo, y otros tópicos migratorios. Donosti: Tercera Prensa.

》Bartra, Eli. 2010. “¿Qué encuentro se busca? Breves cavilaciones sobre el XI Encuentro Feminista Latinoamericano y de El Caribe". Debate Feminista, 41: 197-201.

"Bronstein, Carolyn. 2001. Battling pornography. The American feminist anti-pornography movement 1976-1986. Cambridge: Cambridge University Press.

»Ciriza, Alejandra. 2015. "Construir genealogías feministas desde el sur: encrucijadas y tensiones”. MILLCAYAC, Revista Digital de Ciencias Sociales, II (3): 83-104.

»DAICH, Deborah. 2017. "Aguafiestas porteñas. Sexo y dinero en la micropolítica emocional abolicionista”. Cadernos Pagu, 51: 1-32.

"DAICH, Deborah. 2012. ¿Abolicionismo o reglamentarismo? Aportes de la antropología feminista para el debate local sobre la prostitución. Runa vol. 33, nº 1: 71-84

"DAICH, Deborah y Varela, Cecilia. 2014. "Entre el combate a la trata y la criminalización del trabajo sexual: las formas de gobierno de la prostitución". Delito y Sociedad, 38: 63-86.

"DAICH, Deborah y Varela, Cecilia. 2015. "Trata y trabajo sexual. Problematizaciones antropológicas". Quehaceres, 2: 39-50.

"DUBOIS, Ellen y GORDON, Linda. 1983. "Seeking ecstasy on the battlefield. Danger and pleasure in nineteenth century feminist sexual thought”. Feminist Studies, 9 (1): 7-25.

"DUGGAN, Lisa y Hunter, Nan. 2006. Sex Wars: sex dissent and political culture. New York: Routledge.

"Echols, Alice. 1989. "El ello domado: la política sexual feminista entre 1968-83." En: C. S. Vance (Comp.). Placer y peligro. Explorando la sexualidad femenina. Madrid: Revolución. pp. 79-112.

"Fonseca, Claudia. 2004. “A morte de um gigoló". En: A. Piscitelli, M. F. Gregori y S. Carrara (Orgs.). Sexualidade e Saberes, Convenções e Fronteiras. Río de Janeiro: Garamond. pp. 257-281.

» GRAMMÁTICO, Karin. 2000. "Obreras, prostitutas y mal venéreo. Un Estado en busca de la profilaxis". En: F. Gil Lozano, V. Pita y M. G. Ini (Dirs.). Historia de las mujeres en la Argentina, siglo XX. Buenos Aires: Taurus. pp. 114-133.

" GUY, Donna. 1994. El sexo peligroso. La prostitución legal en Buenos Aires. 1875-1955. Buenos Aires: Sudamericana.

" JULIANO, Dolores. 2002. La prostitución: el espejo oscuro. Barcelona: Icaria.

"LAMAS, Marta. 2017. El fulgor de la noche. El comercio sexual en las calles de la Ciudad de México. México: Océano.

" Mackinnon, Catharine. 1989. "Sexualidad". En: Hacia una teoría feminista del Estado. Madrid: Cátedra. pp. 127-154

" Maqueda Abreu, María Luisa. 2009. Prostitución, feminismos y derecho penal. Granada: Comares.

" PISCITELLI, Adriana. 2005. "Apresentação: gênero no mercado do sexo". Cadernos Pagu, 25: 7-23. 
»RUBIN, Gayle. 1989. "Reflexionando sobre el sexo: notas para una teoría radical de la sexualidad”. En: C. S. Vance (Comp.). Placer y peligro. Explorando la sexualidad femenina. Madrid: Revolución. pp. 113-190.

» VANCE, Carole S. (Comp.) 1989. “El placer y el peligro: hacia una política de la sexualidad”. En: Placer y peligro. Explorando la sexualidad femenina. Madrid: Revolución. pp. 9-50.

» VANCE, Carole S. y Barr Snitow, Ann. 1984. "Toward a conversation about sex in feminism: a modest proposal”. Signs, 10: 126-135.

»VARELA, Cecilia. 2012. “Del tráfico de las mujeres al tráfico de las políticas. Apuntes para una historia del movimiento antitrata en la Argentina (1988-2008)”. Publicar, X (XII): $35-64$.

»VARELA, Cecilia. 2015. "La campaña antitrata en la Argentina y la agenda supranacional”. En: D. Daich y M. Sirimarco (Coords.). Género y violencia en el mercado del sexo. Política, policía y prostitución. Buenos Aires: Biblos. pp. 109-149.

»Villacampa Estiarte, Carolina. 2012. "Políticas de criminalización de la prostitución: análisis crítico de su fundamentación y resultados”. Revista de Derecho Penal y Criminología, 7: 81-412.

»WALKOWITZ, Judith. 1993. “Sexualidades peligrosas”. En: G. Duby y M. Perrot (Comps.). Historia de las mujeres en Occidente. México: Taurus. pp. 64-97.

» WIJERS, Marjan. 2004. “Delincuente, víctima, mal social o mujer trabajadora: perspectivas legales sobre la prostitución”. En: R. Osborne (Ed.).Trabajador@s del sexo. Derechos, migraciones y tráfico en el siglo XXI. Barcelona: Bellaterra. pp. 209-222.

»WILSON, Elisabeth. 1983. "The context of 'between pleasure and danger': the Barnard conference on sexuality”. Feminist Review, 13: 35-41. 